\title{
Bioconectores: ¿Son realmente eficaces en la reducción de las bacteriemias relacionadas con el catéter permanente para hemodiálisis?
}

\author{
Isabel Crehuet Rodríguez, María Albina Bernárdez Lemus, Marta Ramírez Crehuet, Pilar Méndez Briso- \\ Montiano, Carlos Ruiz-Zorrilla López *
}

Diplomados Universitarios en Enfermería, * Facultativo Especialista en Nefrología. Unidad de Diálisis. Hospital Universitario Río Hortega. Valladolid

\section{Resumen}

Uno de los mayores problemas que presentan los catéteres venosos centrales tunelizados para hemodiálisis son las infecciones, por su gravedad y los elevados costes que generan. Por ello, es importante su prevención, ya que, además, el número de catéteres ha aumentado considerablemente en los últimos años.

Objetivos: Realizamos este estudio en nuestra unidad para analizar:

- Eficacia de unos conectores con sistema cerrado (TEGOß) en la prevención de bacteriemia relacionada con el catéter.

- Incidencia de Staphylococcus aureus y gérmenes causantes más frecuentes.

Material y método: Se realizó un estudio retrospectivo, comparativo y transversal durante 800 días, que dividimos en dos periodos iguales. En los primeros 400 se aplicó el protocolo de la unidad a 24 pacientes y en los 400 días siguientes se aplicó el mismo protocolo más los conectores anteriormente citados a 25. En ambos periodos, 19 fueron los mismos pacientes.

Resultados: En el primer periodo se contabilizaron 4 infecciones en 7062 días de catéter y en el segundo 2 infecciones en 8622 días de catéter.

\section{Correspondencia \\ Isabel Crehuet Rodríguez \\ Unidad de Diálisis \\ Hospital Universitario Río Hortega \\ C/ Dulzaina, 2. 47012 Valladolid \\ E-mail: crebel@hotmail.com}

Índice de bacteriemia en ambos periodos: 0,56/1000 y $0,23 / 1000$ respectivamente.

Ninguna infección se produjo por Staphylococcus aureus, siendo el germen más frecuente Staphylococcus coagulasa negativo.

Conclusión: Nuestra conclusión es que los conectores fueron eficaces en la prevención de las bacteriemias ya que redujeron notablemente nuestros, ya bajos, índices de las mismas.

PALABRAS CLAVE:

- CATÉTER VENOSO CENTRAL TUNELIZADO

- BACTERIEMIA

- BIOCONECTORES

- HEMODIÁLISIS

Bioconnectors: Are they really effective in reducing bacteraemia related to permanent catheters for haemodialysis?

\section{Abstract}

One of the greatest problems presented by tunnelled central venous catheters for haemodialysis is infections, on account of their seriousness and the high costs they generate. Prevention is therefore important because, in addition, the number of catheters has increased considerably in recent years.

Objectives: We carried out this study in our unit to analyse:

- Efficacy of closed-system connectors (TEGOß) in the prevention of catheter-related bacteraemia. 
- Incidence of Staphylococcus aureus and most frequent infection-causing germs.

Material and method: A transversal retrospective comparative study was carried out over 800 days, which we divided into two equal periods. In the first 400 days, the unit protocol was applied to 24 patients and in the next 400 days the same protocol was applied plus the above-mentioned connectors to 25 patients. In both periods, 19 of the patients were the same.

Results: In the first period, 4 infections were counted in 7062 catheter days and in the second period, 2 infections in 8622 catheter days.

Bacteraemia index in each period: $0.56 / 1000$ and $0.23 / 1000$ respectively.

No Staphylococcus aureus infection occurred, the most frequent germ being Coagulase-negative Staphylococcus .

Conclusion: Our conclusion is that the connectors were effective in preventing bacteraemia as they notably reduced our already low indices.

\section{KEY WORDS}

- TUNNELLED CENTRAL VENOUS CATHETER

- BACTERAEMIA

- BIO CONNECTORS

- HAEMODIALYSIS en HD que, a su vez, implica una mayor dificultad en la realización y desarrollo de una FAVI; pacientes en los que por su patología se prevé una supervivencia no muy larga; propia elección del paciente, etc.

A pesar de todos los avances realizados en los últimos años en cuanto a biocompatibilidad, diseño, obtención de flujos adecuados, etc, los catéteres aún distan notablemente de estar exentos de mayor número de complicaciones que el resto de accesos vasculares. Generan una mayor morbi-mortalidad debido a trombosis, estenosis de grandes vasos y, sobre todo, debido a las infecciones ${ }^{1,2}$ por la gravedad y los costes que ellas se derivan. Hay que tener en cuenta que éstas son la segunda causa de muerte en los pacientes con enfermedad renal crónica (ERC), por detrás de las enfermedades cardiovasculares ${ }^{3}$. De ahí la importancia de su prevención.

El papel de enfermería en la prevención de bacteriemias relacionadas con el catéter ( $B R C$ ) es fundamental. Las medidas universales de asepsia para cualquier maniobra sobre el catéter como la conexión y desconexión al circuito de HD o la inversión de líneas, deben ser el eje primordial de nuestros cuidados para mantener y prolongar su supervivencia ${ }^{2}$. Otros factores que pueden contribuir a disminuir el número de infecciones como personal entrenado, controles analíticos seriados, utilización de determinados dispositivos, etc. deberían ser tenidos en cuenta en todas las unidades de HD.

Debido a que en nuestra unidad el número de CVCT es bastante elevado, nos planteamos realizar un análisis de la situación en base a los siguientes objetivos:

Estudiar el índice de bacteriemia relacionada con el catéter (BRC), en pacientes portadores del mismo para HD, durante un periodo de 800 días. Durante los 400 primeros hemos aplicado los protocolos de la Unidad y en los 400 últimos, además aplicar el protocolo, hemos utilizado unos conectores cerrados especialmente diseñados para HD.

- Comparar estos índices para valorar la eficacia de dichos conectores en cuanto a la prevención de las infecciones del catéter.

- Analizar la incidencia de Staphylococcus aureus en las BRC e identificar los gérmenes que las producen con mayor frecuencia 


\section{Material y método}

En nuestra Unidad la tasa de CVCT como acceso vascular para HD durante este estudio es de aproximadamente el $45 \%$. Desde hace unos catorce meses aproximadamente (400 días), comenzamos a utilizar unos conectores cerrados para HD (TEGOß), solamente en pacientes portadores de dichos catéteres en programa de HD crónica y en los nuevos que entraban en el programa portando ya un catéter tunelizado. Hemos hecho un estudio retrospectivo, comparativo y transversal del índice de bacteriemias durante el periodo en el que hemos utilizado estos conectores comparándolo con el de los 400 días previos, en los que la única diferencia era la ausencia de dichos conectores. Hemos estudiado el mismo número de días en ambos periodos para evitar sesgos y poder objetivar mejor la eficacia de dichos dispositivos en cuanto a evitar que los gérmenes hagan una colonización intraluminal del catéter. También hemos analizado los tipos de germen que, con mayor frecuencia, causan las bacteriemias en nuestra unidad y la incidencia de Staphylococcus aureus.

Durante los primeros 400 días de estudio hemos aplicado el protocolo que seguimos en la unidad que consta de:

- Manipulación del catéter siguiendo las medidas universales de asepsia (mascarillas para paciente y el personal que interviene, campo, guantes, jeringas, gasas estériles, etc. y como desinfectante solución de clorhexidina acuosa al $2 \%$ ) tanto para la conexión y desconexión del catéter al circuito de HD como para cualquier otra intervención sobre el mismo.

- Conexión al monitor de HD entre dos personas y la desconexión una sola.

- Realización de frotis nasal a los pacientes cada seis meses y más frecuentemente si fuera necesario, es decir, en caso que se detectara algún portador de Staphylococcus aureus.

Los siguientes 400 días hemos aplicado el protocolo de la Unidad anteriormente citado (asepsia más frotis nasales) al que hemos añadido la utilización de unos conectores cerrados especialmente diseñados para HD.

Consideramos BRC la aparición de hemocultivos positivos en ausencia de otro foco de infección. En el caso de BRC, nuestro protocolo contempla la realización de hemocultivos y aplicación de tratamiento antibiótico de forma empírica, en primera instancia y si persiste la fiebre 48-72 horas, se retira el catéter, se inserta otro, si es posible (no siempre lo es) en un lugar distinto y se cultiva la punta del mismo.

Queremos señalar también que a nuestros pacientes no se les aplica antibioterapia profiláctica previa a la inserción del catéter y que el sellado del mismo se realiza con sustancias anticoagulantes (heparina, urokinasa, citrato, etc.). En ningún caso, a priori, con antibióticos.

Los nuevos conectores que se acoplan a los catéteres se han recambiado al comenzar la primera sesión de HD de la semana, una vez por semana.

Hemos incluido a todos aquellos pacientes que durante los periodos de tiempo estudiados eran portadores de CVCT para HD, excluyendo del mismo a los portadores de catéteres temporales o no contabilizando los días del catéter temporal, cuando éste era previo a la colocación del tunelizado. Todos los catéteres eran de tipo palindrómico, con un diámetro de 14,5 French y diferentes longitudes según la altura del paciente y el lugar de inserción.

Durante los 800 días se estudiaron 24 pacientes $(n=24)$ en el primer periodo, de los cuales se excluyeron 5 en el segundo porque utilizaron una FAVI como acceso vascular. Los 19 restantes se estudiaron también en el segundo, a los que se añadieron 6 nuevos pacientes que comenzaron en el programa de HD de la unidad, lo que supone una muestra en este segundo periodo de 25 pacientes $(n=25)$

Todos los pacientes incluidos en el estudio fueron informados del mismo, aceptando su realización.

Los autores declaran que no existe conflicto de intereses.

El análisis estadístico de los datos se realizó con el programa SPSS 15.0 para Windows expresándose como la media junto con la desviación estándar para las edades y como la mediana con el rango intercuartílico para el tiempo de permanencia en HD. La comparación entre los resultados se realizó con el programa EPIDAT 3.0, siendo $p$ estadísticamente significativa cuando $p<0,05$.

\section{Resultados}

Durante el primer periodo, de los 24 pacientes, 10 son mujeres y 14 son hombres; la media de edad es de 68,79 $\pm 15,14$ años, siendo la mediana de permanencia en HD de 44,5 meses $(28,75-67,25)$. 
De los catéteres, 19 estaban insertados en vena yugular derecha, 4 en vena yugular izquierda y 1 en vena femoral izquierda.

Se contabilizaron un total de 7.062 días de catéter.

Se detectaron 4 infecciones con hemocultivos positivos causadas: una por un germen tipo Streptococcus Gram + (Kokuria kristinae); otras dos en una misma paciente, causadas por un Streptococcus sanguinii y por un Gemella morbillorum; otra por Staphylococcus coagulasa negativo.

Se detectaron en los frotis nasales seis portadores de Staphylococcus aureus que fueron tratados con mupirocina tópica, revirtiendo dicha condición de portador nasal, pese a la cual no se produjo infección alguna del catéter por dicho germen. En ningún caso tampoco hubo que retirar ningún catéter.

El índice de BRC en este primer periodo es de 0,56/1000 días de catéter. (Fig.1)

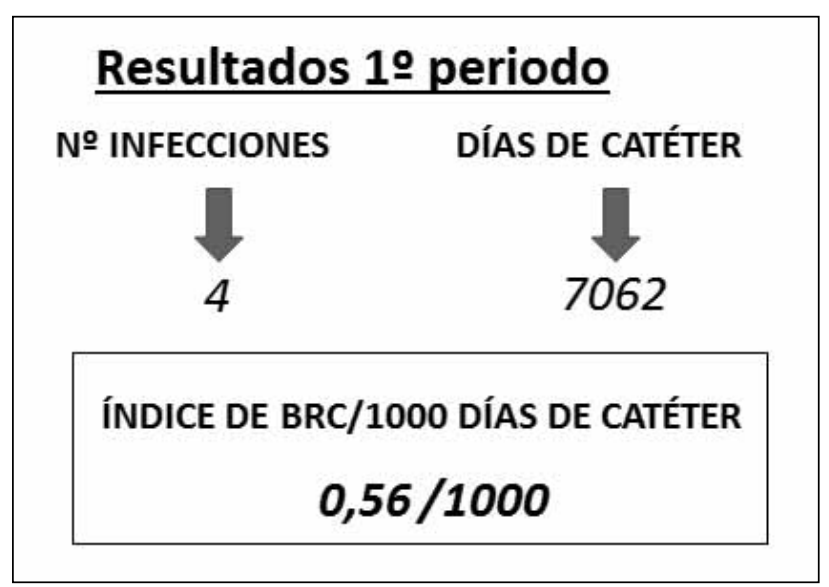

Fig. 1

Durante el segundo periodo estudiamos un total de 25 pacientes. De ellos, 10 son mujeres y 15 hombres. La media de edad es de 70,44 $\pm 14,27$ años. La mediana de permanencia en HD es de 29 meses (17-67); los lugares de inserción de los catéteres son: 18 en vena yugular derecha, 4 en yugular izquierda, 2 en femoral derecha y 1 en vena femoral izquierda.

Contabilizamos un total de 8622 días de catéter.

Aparecieron 2 infecciones con hemocultivos positivos, en un caso por una enterobacteria ( $E$. Coli) y en el otro por un Staphylococcus Coagulasa negativo.
Aparecieron 2 frotis nasales positivos para Staphylococcus aureus, que revirtieron con tratamiento tópico. No se produjo ninguna infección por dicho germen ni hubo que cambiar catéter alguno por infección a lo largo de este segundo periodo.

El índice de BRC es de 0,23/1000 días de catéter. (Fig. 2)

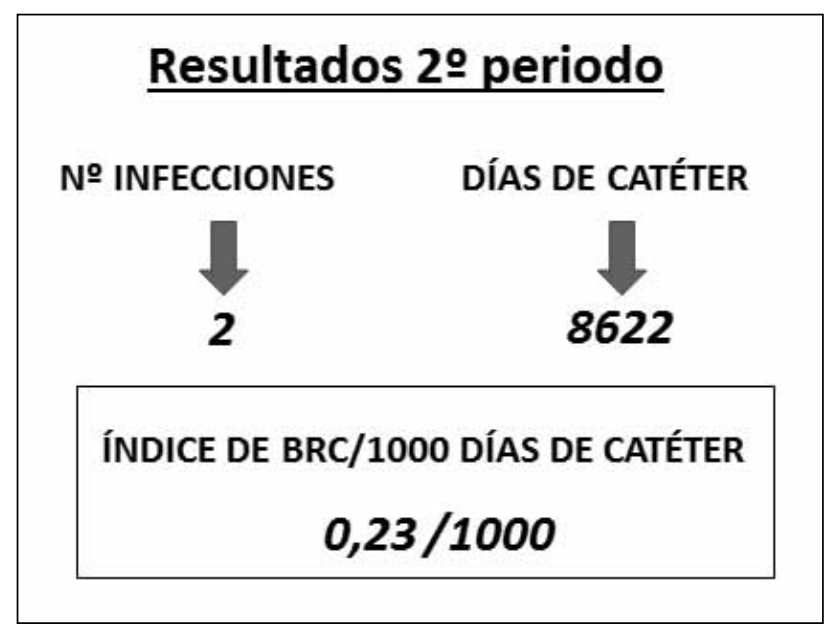

Fig. 2

\section{Discusión}

En el hecho de tener una tasa de BRC tan baja $(<1 / 1000$ días-catéter: excelente $)^{4}$ influye, sin duda, la revisión y cumplimiento de los protocolos de la Unidad, en los que de manera sistemática se incluyen los frotis nasales además de realizar la conexión siempre entre dos personas (una enfermera/o y un técnico en cuidados auxiliares de enfermería).

Sabemos que las conexiones del catéter son el punto más frecuente de entrada de los gérmenes y que las muchas manipulaciones del personal de enfermería sobre ellas pueden incidir directamente sobre las infecciones; de ahí la importancia de que, como señala Albalate M. et al., este personal de enfermería esté debidamente preparado y que disponga del tiempo necesario adecuando la ratio paciente/enfermera. ${ }^{5}$

El uso de estos conectores especialmente diseñados para los catéteres de $\mathrm{HD}\left(\mathrm{TEGO}{ }^{\circledR}\right)^{6}$, a priori, nos debe hacer pensar que disminuiría la cantidad de infecciones, puesto que se reduce notablemente el número de exposiciones de la luz del catéter al exterior. La posibilidad de utilizarlos nos pareció un paso más a la hora de mejorar nuestros índices de BRC. Por supuesto que lo principal a tener en cuenta, tal como concluyen en su 
estudio Martínez Aranda M.A. et al., son las medidas universales de asepsia ${ }^{7}$. En este estudio no encontraron unas diferencias significativas entre utilizar o no los conectores. Parten de una muy baja tasa de BRC, Io que unido al hecho de que el tiempo estudiado no es muy largo, el factor tiempo influye en la tasa de BRCpueden justificar que no encontraran diferencias. Cobo J.L. et al. en un estudio comparativo entre la conexión directa y la conexión con bioconectores partían de tasas de BRC mucho más elevadas y consiguieron disminuirlas considerablemente al utilizar estos últimos ${ }^{8}$. Buenos resultados obtuvieron también McAfee $\mathrm{N}$. et al. en un estudio realizado en pacientes pediátricos, en el que demostraron reducir su tasa de BRC a la mitad con el uso de estos conectores 9 .

Sabemos que existen autores que abogan por la profilaxis antibiótica previa a la inserción de un CVCT para HD, así como el sellado del mismo con antibiótico y anticoagulante. En nuestra Unidad ninguna de las dos medidas se realiza, salvo casos extremos, como la existencia de infecciones recurrentes y la ausencia de otros vasos permeables donde alojar el catéter. En estos casos, hemos sellado el catéter con antibiótico además de anticoagulante durante un tiempo más o menos largo. No hemos tenido ningún caso de este tipo durante la realización del estudio.

Al partir de una tasa tan baja de BRC pensábamos que el empleo de estos conectores apenas la disminuiría. Aún así, la hemos reducido más de un $50 \%$, por lo que creemos que cualquier dispositivo que pueda ayudar a que exista un menor número de infecciones debe ser bien recibido.

\section{Conclusiones}

En nuestra Unidad, hemos conseguido una tasa de BRC muy baja ( $<1 / 1000$ días de catéter), lo que permite incluirnos dentro del rango de la excelencia (Tabla 1). Esto es debido, sin duda, a la aplicación de las medidas

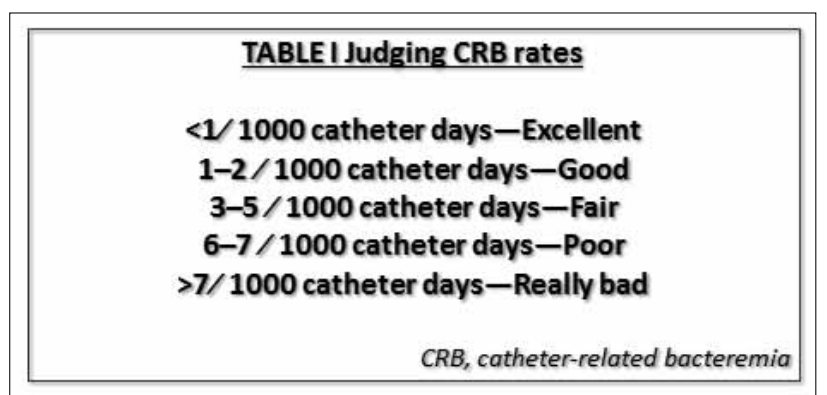

Tabla 1. universales de asepsia, avaladas por el hecho de que la manipulación de los catéteres se realiza por personal debidamente entrenado y por la detección y reversión de los portadores de Staphylococcus aureus, gracias a la realización de los frotis nasales.

La utilización de los conectores ha reducido alrededor de un $60 \%$ ( $p$ estadísticamente muy significativa, $p<0,0001$ ) la ya baja tasa de bacteriemia que teníamos, ya que el uso de los mismos disminuye considerablemente la exposición de la luz de los catéteres al exterior y la manipulación de los mismos, por lo que consideramos que suponen una gran ayuda para disminuir la tasa de BRC. (Fig. 3)

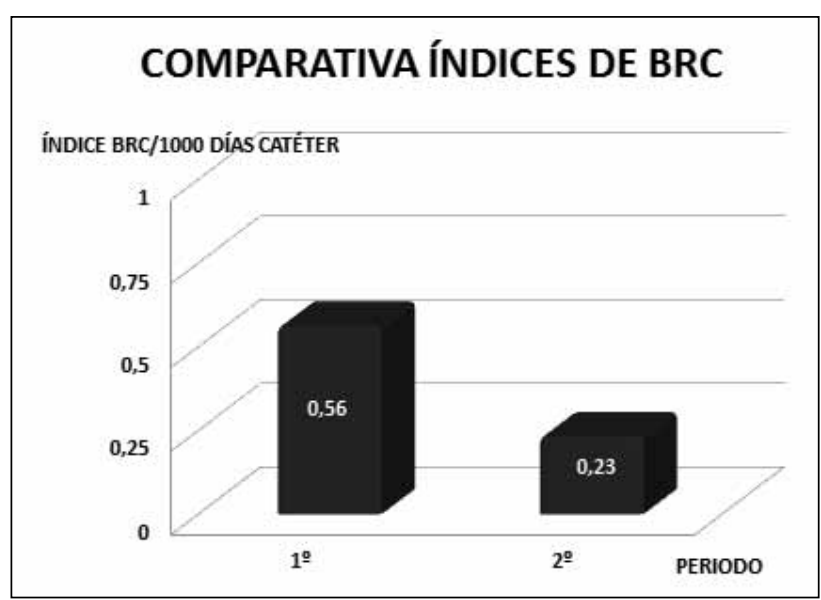

Fig. 3

En ambos casos, debemos destacar el papel de enfermería en la obtención de estas tasas, por su implicación en la elaboración, cumplimiento y actualización de los protocolos de cuidados del catéter.

Por otro lado, podemos decir que, al menos durante los periodos estudiados, hemos conseguido eliminar el Staphylococcus aureus como causante de BRC en nuestra unidad, siendo el germen más frecuente el Staphylococcus Coagulasa negativo. 


\section{Bibliografía}

1. Rodríguez Hernández J.A., González Parra E., Gutiérrez Julián J.M., Segarra Medrano A., Almirante B., Martínez M. ${ }^{a}$ T., et al. Catéteres venosos centrales. Guías de acceso vascular en hemodiálisis. Nefrología 2005; 25 Supl.(1): 64-92

2. National Kidney Foundation. KDOQI Clinical Practice Guidelines and Clinical Practice Recommendations for 2006 Updates: Hemodialysis Adequacy, Peritoneal Dialysis Adequacy and Vascular Access. Am J Kidney Dis 2006; 48 (supl 1): S1-S322.

3. Registro Español de Enfermos Renales. Informe 2006 de diálisis y trasplante renal en España. Nefrología 2009 (29): 525-533.

4. [Beathard GA, Urbanes A. Infection associated with tunneled hemodialysis catheter. Semin Dial 2008; 21 (6): 528-538. [Pubmed]

5. Albalate $M$, Pérez García $R$, De Sequera $P$, Alcázar $R$, Puerta M, Ortega M, Mossé A, Crespo E. ¿Hemos olvidado lo más importante para prevenir las bacteriemias en pacientes portadores de catéteres para hemodiálisis? Nefrología 2010.30 (5): 573-577.

6. http://www.victus.com/esp/products/conector-tego/ medical-coector-tego.html Consultado. Abril 2012
7. Martínez Aranda MA, Arribas Cobo $P$, Ruiz Álvarez A, Rodríguez Estaire J, Callejo Cano I, Díaz de Argote $P$, Sáenz Santolaya $A$, Cerrajero Calero R, Liébana Pamos B, Guimerá Ferrer- Sama MA, Larico Cuno M, Quesada Armentero MT, Herrera Martín E, Vinagre Rea G, García Estévez S. Eficacia del uso de bioconectores para los catéteres centrales de hemodiálisis. Rev Soc Esp Enferm Nefrol 2011; 14 (2): 106/111.

8. Cobo Sánchez JL, Sainz Alonso RA, Vicente Jiménez MY, Cepa García H, Pelayo Alonso R, Menezo Viadero $\mathrm{R}$, Ibarguren Rodríguez $\mathrm{E}$, Pérez Garmilla AI, Rojo Tordable M, Begines Ramírez A, Sola García MT, Alonso Nates R. Estudio comparativo de incidencia de bacteriemias relacionadas con el catéter de hemodiálisis: bioconectores frente a conexión directa. Rev Soc Esp Enferm Nefrol 2011; 14 (4): 230-235.

9. McAfee N, Seidel K, Watkins S, Flynn JT. A continuous quality improvement project to decrease hemodialysis catheter infections in pediatric patients: use of a closed luer-lock access cap. Nephrol Nurs J. 2010; 37(5): 541-544.

10. Crehuet Rodríguez I, Méndez Briso-Montiano P. Supervivencia de un catéter: un reto y un logro de enfermería. Rev Soc Esp Enferm Nefrol 2011; 14 (3): 189-194. 